\title{
Transcapillary Protein Flux Following Blood Volume Modification in Dog
}

\author{
Kenju Miki, ${ }^{*}$ Hiroshi Nose, Yoshifumi TanaKa, ${ }^{* *}$ \\ and Taketoshi MoRimoto \\ Department of Physiology and ${ }^{* *}$ Department of Anesthesiology, \\ Kyoto Prefectural University of Medicine, \\ Kamigyo-ku, Kyoto, 602 Japan
}

\begin{abstract}
The net fluid and protein movements between intravascular and interstitial space following blood withdrawal and retransfusion of $15 \%$ of circulating blood volume were measured in dogs using a continuous monitoring method of circulating blood volume. A significant $(p<0.01)$ increase in transvascular fluid shift was observed after the start of blood withdrawal and a new equilibrium state was reached within 15 to $20 \mathrm{~min}$. Associated with the fluid shift, a significant increase in plasma protein of about $1 \mathrm{~g}$ was observed. On the other hand, blood retransfusion caused significant $(p<0.01)$ increases in the shift of fluid and protein from intravascular space to interstitial space. The magnitudes of the shift of fluid and protein were almost identical in both blood withdrawal and retransfusion. The Kedem-Katchalsky transport equation was applied to the results obtained in the present study in order to analyze the relative role of diffusion and convection and to estimate the reflection coefficient for protein. A significant $(p<0.01)$ linear relationship was observed between fluid and protein movement. These results suggest that the convective process is involved in the shift of protein between intravascular and interstitial space observed after blood volume modification.
\end{abstract}

Key Words: capillary filtration, plasma oncotic pressure, transcapillary protein flux, blood volume change.

The distribution ratio of protein between plasma and interstitium is the major determinant of the fluid volume distribution between intravascular and interstitial fluid compartments. Early recovery of plasma protein, which has been observed after hemorrhage (SKILLMAN et al., 1967; ZolLINGER, 1972), suggests the protein shift from interstitium to plasma. The increase in intravascular protein content

Received for publication June 23, 1984

* Present address: Department of Physiology, University of Occupational and Environmental Health, School of Medicine, Yahatanishi-ku, Kitakyushu, 807 Japan

三木健寿，能勢 博，田中義文，森本武利 
plays a significant role in the recovery of plasma volume after hemorrhage. It has been reported that the early plasma protein recovery after hemorrhage was caused by lymphatic protein transport or direct transcapillary shift of protein from interstitial space to blood stream (COPE and Litwin, 1962; NOER and LASSEN, 1978; Pirkle and GANN, 1976). Zollinger (1972) showed that the protein flow via the thoracic duct was inadequate to account for the rapid refill of protein mass which was observed within $1 \mathrm{hr}$ after hemorrhage. Recently, GRANGER et al. (1981) demonstrated the shift of plasma protein from the interstitial space to blood by convection in the intestine. But there is little evidence to suggest that direct transcapillary shift of protein occurs after hemorrhage.

In the present study, net transcapillary protein flux between intravascular and extravascular spaces during blood withdrawal and retransfusion was determined using the continuous monitoring method of blood volume and plasma protein concentration. A significant change was observed in intravascular protein mass immediately after blood volume modification. Based on the results, the mechanisms involved in protein exchange across the capillary wall are discussed.

\section{METHODS}

Seven mongrel dogs, averaging $9.5 \mathrm{~kg}$ in body weight, were splenectomized a week prior to investigation. On study days, anesthesia was induced with thiopental sodium $(25 \mathrm{mg} / \mathrm{kg})$. Each dog was weighed, placed in the supine position, intubated, and ventilated with $1-2 \%$ halothane in $30 \% \mathrm{O}_{2}-70 \% \mathrm{~N}_{2} \mathrm{O}$ by means of a volume-limited respirator. Catheters were placed in the left femoral artery and inferior vena cava through the left femoral vein for recording arterial and central venous pressures. An arteriovenous shunt was established using the right femoral artery and vein, and it was connected to an extracorporeal circuit and used for obtaining measurements and carrying out blood volume modifications. Sodium heparin was administered at an initial dose of $5 \mathrm{mg} / \mathrm{kg}$ with a maintenance dose thereafter of $2.5 \mathrm{mg} /(\mathrm{kg} \cdot \mathrm{hr})$.

Protocol. Blood withdrawal and retransfusion were performed once or twice on each dog. The volume of the withdrawal or retransfusion was $15 \%$ of the measured circulating blood volume over a 10 -min span, and 50 -min equilibrium stages were interwoven between blood volume modifications. To control blood volume within the animal, arterial blood drawn from the femoral artery was by-passed to the femoral vein through a blood reservoir by means of a flow pump on each side of the reservoir. The flow rate of the pump on the arterial side was fixed at $40 \mathrm{ml} /$ min; that on the venous side was controlled with a photo-cell liquid level detector and a mini-computer (HITAC-10). For control and recovery periods, the pump on the venous side was fixed at the same rate as that of the arterial side, while blood volume in the reservoir was maintained at a constant level. To remove blood from the animal or to reinfuse it, the blood volume in the reservoir was increased or 
decreased by changing the pump rate on the venous side. The details and accuracy of the system have been described elsewhere (TANAKA et al., 1981).

Measurements. Blood volume, hematocrit of circulating blood, and plasma colloid osmotic pressure were monitored continuously using previously described methods (MORImoto et al., 1981). Briefly, blood was led by a pump to the arteriovenous shunt which contains a conductivity cell for hematocrit determination, a well-type gamma counter for continuous blood volume measurement (using dilution method of ${ }^{51} \mathrm{Cr}$ labelled erythrocyte) and a needle type oncotic pressure probe for plasma colloid osmotic pressure determination. In this paper, the intravascular space was defined as the circulating space of erythrocyte labelled with ${ }^{51} \mathrm{Cr}$.

At 10-min intervals, $150 \mu 1$ arterial blood samples were drawn for the determinations of the hematocrit and plasma protein concentration by the refractometric method. The hematocrit reading of each arterial sample was done in triplicate. The micro-centrifugation method was used to calibrate the continuous determination of the hematocrit. Hematocrit and blood volume determination accuracy was analyzed in detail and has been published elsewhere (TANAKA et al., 1976, 1981). The results showed that the maximum deviation of hematocrit determination was $\pm 2.0 \%$ and the accuracy of blood volume determination was within $1 \%$ of the coefficient of variation, while that of the plasma protein concentration determination was $2 \%$ (KAKIUCHI et al., 1979).

The amount of net transvascular fluid shift was calculated as the difference between modified blood volume and measured blood volume circulating in the animal and the reservoir (MIKI, 1981). The plasma volume circulating in the animal and the reservoir was calculated from the blood volume and hematocrit. The protein mass within the animal and the reservoir was calculated from the plasma protein concentration and the circulating plasma volume. The constancy of erythrocyte volume circulating in the animal and the reservoir calculated from total blood volume and hematocrit indicated the validity of the blood volume determination technique.

The data were analyzed by using standard statistical techniques and the null hypothesis of each of the studied variables was rejected at $1 \%$ level.

Analysis. The transcapillary protein transport consists of convective and diffusive components (KEDEM and KATCHALSKY, 1958) and can be shown as

$$
J \mathrm{p}=J_{\mathrm{v}}(1-\sigma) \bar{C} \mathrm{p}+P S \Delta C,
$$

where $J \mathrm{p}$ is the net transcapillary protein flux, $J_{\mathrm{V}}$ is the net transcapillary water flux, $\sigma$ is the reflection coefficient for protein, $\bar{C}$ p is the average protein concentration across the capillary wall, i.e., $(C \mathrm{i}+C \mathrm{p}) / 2(C \mathrm{p}$ is the plasma protein concentration and $C \mathrm{i}$ is the interstitial fluid protein concentration), $P S$ is the permeabilitysurface area product, and $\Delta C$ is the transcapillary protein concentration gradient $(C \mathrm{p}-\mathrm{Ci})$. By applying Eq. 1 to the results, the mechanisms responsible for the transcapillary protein transport after blood volume modifications were analyzed. 


\section{RESULTS}

In Fig. 1 the changes in the net transvascular fluid movement and intravascular protein mass are shown as the difference from the control values. Blood withdrawal and retransfusion elicited fluid movement across the capillary wall and then a new equilibrium state was reached within 15 to $20 \mathrm{~min}$. The significant changes in net protein flux or intravascular protein mass which amounted to 0.6 to $1.0 \mathrm{~g}$ were observed during blood withdrawal and retransfusion. During blood withdrawal, the intravascular protein mass was increased significantly by $0.9-1.0 \mathrm{~g}$. During blood retransfusion, the significant decrease by $0.6-0.9 \mathrm{~g}$ was observed in the intravascular protein mass. The decrease or increase in the fluid and protein
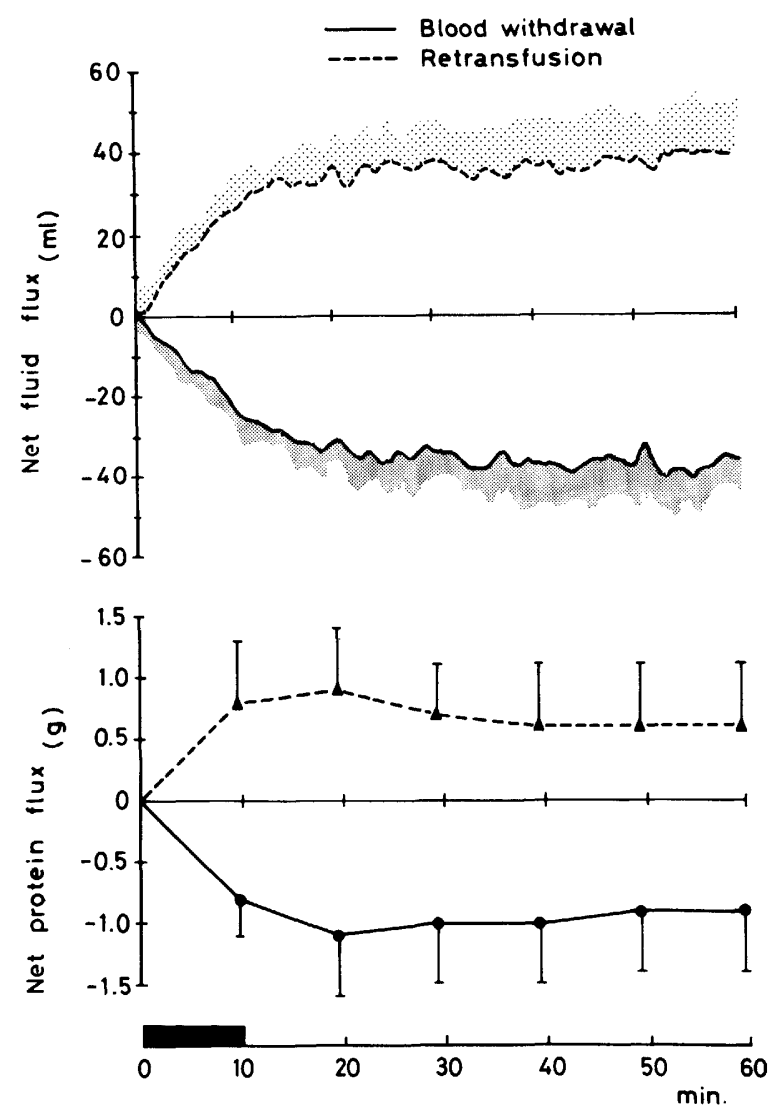

Fig. 1. The net transcapillary fluid and protein fluxes due to blood withdrawal and retransfusion. The bar on the time scale indicates the period of blood volume modification. The data are presented as the difference from the control value. The means and 1 S.D. of 7 experiments are shown. Positive values of the net fluid and protein fluxes indicate the shift from intravascular to interstitial space, whereas the negative values indicate the shift from interstitial to intravascular space. 


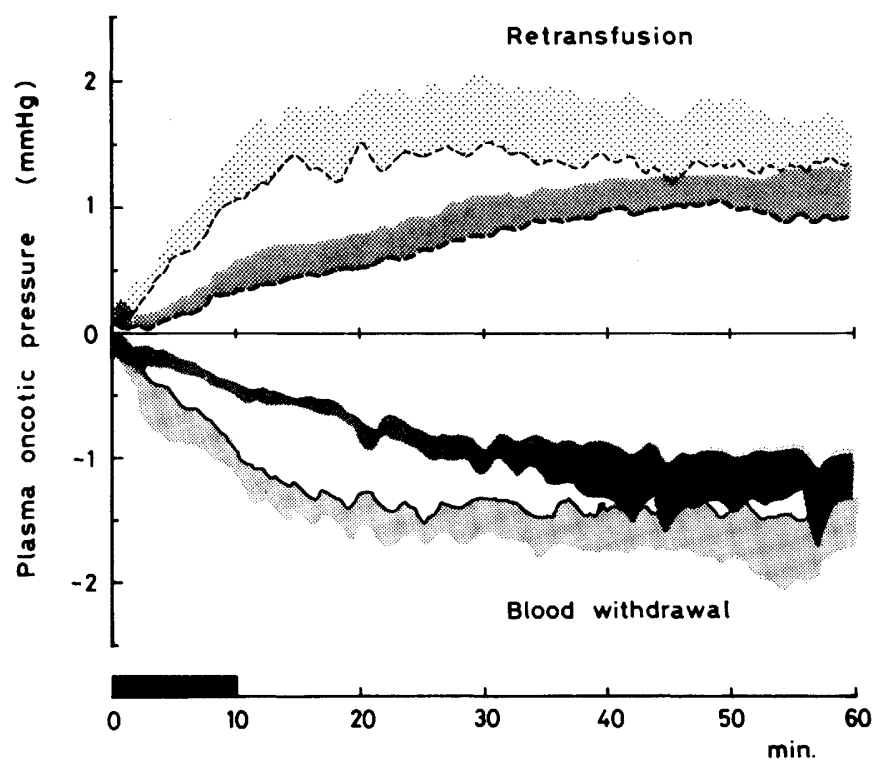

Fig. 2. Changes in measured plasma oncotic pressure (inner lines) and simulated values (outer lines) which were obtained from the Landis-Pappenheimer equation assuming the intravascular protein mass remains constant during blood volume modification. The bar on the time scale indicates the period of blood volume modification. The means and 1 S.D. of 7 experiments are shown.

movement showed a mirror image throughout blood volume modification and recovery phases. No significant difference was observed in the absolute values of the changes of protein and fluid volume.

Figure 2 shows the measured change in plasma oncotic pressure (inner lines) and simulated change in plasma oncotic pressure calculated on an assumption that plasma protein should not shift across capillary wall (outer lines). The simulated values were obtained from the Landis-Pappenheimer equation: $\pi_{\mathrm{prasma}}=2.1 C+$ $0.16 C^{2}+0.009 C^{3}$ (LANDis and PAPPENHEIMER, 1963) based on the plasma protein concentration calculated from measured change in plasma volume and initial intravascular protein content (averaging $25.6 \mathrm{~g}$ ), assuming that intravascular protein mass remains constant throughout the experimental period. On blood withdrawal, the observed changes in plasma oncotic pressure decreased linearly from the onset of blood withdrawal to $30 \mathrm{~min}$ and thereafter the level of about $-0.94 \mathrm{mmHg}$ was maintained. On blood retransfusion, the measured value of plasma oncotic pressure increased linearly to about $35 \mathrm{~min}$ and was maintained at about $0.97 \mathrm{mmHg}$ from 35 to $60 \mathrm{~min}$ after the onset of retransfusion. There was no significant difference in the magnitude of the change in measured plasma oncotic pressure between blood withdrawal and retransfusion. But there was a significant difference between measured plasma oncotic pressure and simulated plasma oncotic pressure. 


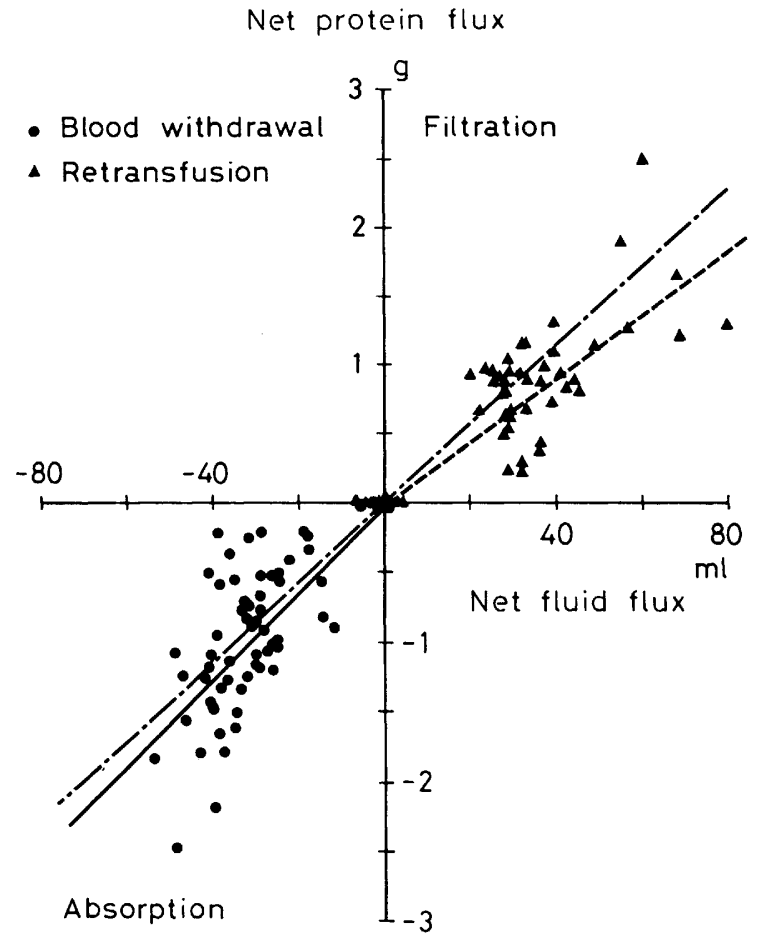

Fig. 3. Net protein flux $\left(\int J \mathrm{p}\right)$ between intravascular and interstitial space is plotted as a function of net transvascular fluid flux $\left(\int J_{\mathrm{V}}\right)$. Regression lines for blood withdrawal (solid line, $\int J_{\mathrm{p}}=0.034 \int J_{\mathrm{V}}-0.02 ; r=0.84, p<0.01$ ), for retransfusion (dotted line, $\int J_{\mathrm{p}}=$ $0.023 \int J \mathrm{~V}-0.03 ; r=0.80, p<0.01$ ) and for both conditions (broken line, $\int J_{\mathrm{p}}=0.028 \int J_{\mathrm{V}}$ $+0.13 ; r=0.94, p<0.01)$ are shown.

The difference was about $0.6-0.7 \mathrm{mmHg}$ at 10 to $25 \mathrm{~min}$ in blood withdrawal and $0.5-1.0 \mathrm{mmHg}$ at 5 to $30 \mathrm{~min}$ in blood retransfusion. When the movement of the protein mass was taken into consideration for the calculation of plasma oncotic pressure, this discrepancy disappeared.

Net gain or loss of the intravascular protein mass $\left(\int J \mathrm{p}\right)$ was plotted as the function of net transvascular fluid flux $\left(\int J_{v}\right)$ in Fig. 3. Significant relationships between the net protein flux and the transvascular fluid flux were observed as follows: For blood withdrawal, the relationship became

$$
\int J \mathrm{p}=0.034 \int J_{\mathrm{v}}-0.02,(r=0.84, n=64, p<0.01),
$$

and for retransfusion,

$$
\int J \mathrm{p}=0.023 \int J_{\mathrm{v}}-0.03,(r=0.80, n=63, p<0.01) .
$$


When the data of both blood withdrawal and retransfusion were used for the regression analysis, the relation became

$$
\int J \mathrm{p}=0.028 \int J \mathrm{v}+0.13,(r=0.94, n=127, p<0.01) .
$$

There was no statistically significant difference between the slopes for blood withdrawal (0.034) and for retransfusion (0.023). According to Eq. 1, the slope of the regression line represents the $(1-\sigma) \bar{C} \mathrm{p}(\mathrm{g} / \mathrm{ml})$ at higher levels of $J \mathrm{v}$. The average value of plasma protein concentration was 5.4 and $5.3(\mathrm{~g} / 100 \mathrm{ml})$ in blood withdrawal and retransfusion, respectively. Assuming that the ratio of protein concentration between interstitial and plasma ranges from 0.2 to 0.9 (RENKIN, 1979), we estimated the range of $\bar{C}$ p. We could then calculate $\sigma$ from $\bar{C} \mathrm{p}$ and the slope of the regression line between $J \mathrm{~V}$ and $J \mathrm{p}$. The calculated value of $\sigma$ was lower than 0.6.

\section{DISCUSSION}

The fluid distribution between intravascular and interstitial space is altered by blood volume modification and plays a role in blood volume restitution. The rapid transcapillary fluid movement that occurs immediately after blood volume modification can be monitored by continuous determination of circulating blood volume and hematocrit (MIKI, 1981; МоRIмото et al., 1981). In the present study, associated with the transcapillary fluid movement, significant gain or loss of intravascular protein mass amounting to $1 \mathrm{~g}$ was observed following blood withdrawal or retransfusion. This shift of protein caused the significant change in plasma oncotic pressure.

The possible mechanisms of protein movement between plasma and interstitial fluid space are the lymphatic drainage and direct transcapillary shift. However, the contribution of the lymphatic system to rapid and reversible protein movement observed in this experiment seems to be negligible, because the rate of lymphatic protein transport has been reported to be $10 \mathrm{mg} / \mathrm{min}$ in control dogs, and both the flow rate of lymph and the lymph protein concentration were either little changed or fell after hemorrhage of $10-15 \%$ of blood volume (ZollingER, 1972). It has also been reported that increased lymphatic protein return became noticeable at 6 to $24 \mathrm{hr}$ after hemorrhage (Cope and Litwin, 1962; Pirkle and GanN, 1976). Although the fluid shift into the interstitium due to retransfusion increases the driving force for the lymphatic return, the significant decrease in intravascular protein mass was observed during retransfusion. Therefore, the protein transport via a lymphatic system plays a minor part in the shift of about $1 \mathrm{~g}$ of protein observed at the 10-20th min after blood volume modification. This protein movement might be attributed to the direct transvascular exchange. ZolliNGER (1972) demonstrated that $4.4 \mathrm{~g}$ of albumin were conserved following hemorrhage while protein transport via thoracic duct remained constant. OsTEEN and KLEBANOFF

Vol. 34, No. 6, 1984 
(1971) showed rapid refill of protein after plasmapheresis in baboons and concluded that the thoracic duct was inadequate to account for the protein movement. In agreement with the previous reports, the direct migration of protein across the capillary wall after blood volume modification was suggested. But there is little direct evidence or analysis that accounts for the mechanisms involved in transcapillary protein transport after blood volume modification.

The transcapillary protein transport has both a convective and a diffusive component (Eq. 1). Because the protein concentration of plasma is higher than that of interstitial fluid, diffusive protein fluxes are directed toward the interstitium. However, a significant amount of protein moved against a protein concentration gradient when transvascular fluid shift from interstitium to blood occurred during blood withdrawal. Conversely, blood retransfusion caused the loss of intravascular protein mass concomitantly with transvascular fluid shift from intravascular space to interstitium. In addition, the time courses of the changes in transvascular fluid shift and protein movement were almost similar in both conditions (Fig. 1). Also, a significant linear relationship between fluid and protein fluxes was obtained in both conditions (Fig. 3). These data suggest that the diffusive component plays a minor role in the rapid movement of a significant amount of protein at increased transvascular fluid movement caused by blood volume modification. Therefore, it is suggested that the observed protein movement following blood volume modification was caused primarily by convection. GRANGER et al. (1981) clearly showed, using steady-state lymphatic protein flux data, that significant quantities of plasma protein are removed from the interstitium and enter the blood stream. They suggested that convection accounts for approximately $80-90 \%$ of the total net transcapillary protein movement at normal and increased capillary filtration rates in a dog's intestine. We were able to measure $J_{\mathrm{V}}$ and $J$ p of Eq. 1 directly and this new approach allowed us to analyze the transvascular protein movement under a nonsteady-state. Our conclusion based on the direct measurement of $J_{\mathrm{v}}$ and $J_{\mathrm{p}}$ supports Granger's conclusion obtained using steady-state lymphatic protein flux data.

It is generally recognized that the value of $\sigma$ varies with the capillary type. For example, RENKIN (1979) showed 3-4 times difference in lymph/plasma concentration ratios for endogenous plasma proteins between liver and leg. In liver, the ratios range between 0.53 and 0.85 while in leg, the ratios range between 0.13 and 0.28. No attempts have been made to estimate the mean value of $\sigma$ for the whole body but we could estimate $\sigma$ from the slope of the regression line $[(1-\sigma) \bar{C}$ p] and the average protein concentration across the capillary $(\bar{C} \mathrm{p})$. The values of $\sigma$ obtained by us were lower than 0.6 . The low values suggest that the protein exchange following blood withdrawal might have occurred at the fenestrated or discontinuous capillary bed, such as, in the liver or gastrointestinal tract. Especially in liver, an extremely high value of $0.9-0.6$ has been reported for lymph/plasma concentration ratios for endogenous plasma proteins (RENKIN, 1979). It has also 
been shown that the capillary bed in the visceral organ is an important area for transcapillary shift of water and electrolytes after hemorrhage. MARTY and ZWEIFACH (1971) have demonstrated that evisceration in dogs prevents hemodilution after hemorrhage. Our results and other previous reports strongly suggest that the transcapillary shifts of water and protein take place in the splanchnic bed accompanying the transvascular fluid shift.

In summary, the transcapillary shift of protein seems to be caused in the following sequence. Modification of circulating blood volume elicits a change in capillary pressure and the balance of the Starling's force across the capillary wall is disturbed. The unbalance of pressure causes the fluid movement between the intracapillary and the interstitial space. The splanchnic area seems to be the major site of rapid transcapillary fluid movement during blood volume modification. Because the reflection coefficient for protein and the concentration gradient of protein across the capillary wall are low in the splanchnic area, increased transcapillary fluid flux causes the significant shift of protein by convection from the interstitium to the blood stream during blood withdrawal, and from the intravascular to the interstitial space during retransfusion.

This study was supported in part by Grants-in-Aid for Scientific Research from the Ministry of Education, Science and Culture of Japan (Grants No. 56570063, 57480127, and 59480115).

\section{REFERENCES}

Cope, O. and Litwin, S. B. (1962) Contribution of the lymphatic system to the replenishment of the plasma volume following a hemorrhage. Ann. Surg., 156: 655-667.

Granger, D. N., Perry, M. A., Kvietys, P. R., and Taylor, A. E. (1981) Interstitium-toblood movement of macromolecules in the absorbing small intestine. Am. J. Physiol., 241 (Gastrointest. Liver Physiol., 4): G31-G36.

Kakiuchi, Y., Arai, T., Horimoto, M., Kikuchi, Y., and Koyama, T. (1979) A new needletype colloid osmometer for continuous determination of blood oncotic pressure. $A m$. $J$. Physiol., 236 (Renal Fluid Electrolyte Physiol., 5): F419-F422.

KEDEM, O. and KATCHALSKY, A. (1958) Thermodynamic analysis of biological membranes to nonelectrolytes. Biochim. Biophys. Acta, 27: 299-346.

LANDis, R. M. and PAPPENHEIMER, J. R. (1963) Exchange of substances through capillary walls. In: Handbook of Physiology, Circulation, Sec. 2, Vol. II, Am. Physiol. Soc., Washington D. C., p. 974.

Marty, A. T. and ZweIFACH, B. W. (1971) Splanchnic contribution to transcapillary refill after hemorrhagic shock. Ann. Surg., 174: 131-136.

Miki, K. (1981) Dynamics of the plasma-interstitial fluid distribution and transcapillary pressure difference. Jpn. J. Physiol., 31: 917-929.

Morimoto, T., Miki, K., Nose, H., Tanaka, Y., and Yamada, S. (1981) Transvascular fluid shift after blood volume modification in relation to compliances of the total vascular bed and interstitial fluid space. Jpn. J. Physiol., 31: 869-878.

NOER, I. and LASSEN, N. A. (1978) Evidence of active transport (filtration ?) of plasma proteins across the capillary wall in muscle and subcutis. Lymphology, 11: 133-137.

OsteEn, R. T. and KLebanoff, G. (1971) Early plasma protein recovery after total volume plasmapheresis in baboons. Surgery, 69: 276-283. 
PIRKLE, J. C., Jr. and GanN, D. S. (1976) Expansion of interstitial fluid is required for full restitution of blood volume after hemorrhage. J. Trauma, 16: 937-947.

RENKIN, E. M. (1979) Relation of capillary morphology to transport of fluid and large molecules: A review. Acta Physiol. Scand. (Suppl.), 463: 81-91.

Skillman, J. J., Awwad, H. K., and Moore, F. D. (1967) Plasma protein kinetics of the early transcapillary refill after hemorrhage in man. Surg. Gynecol. Obstet., 125: 983-996.

TANAKA, Y., Morimoto, T., Miki, K., Nose, H., and MiYAZAKI, M. (1981) On-line control of circulating blood volume. Jpn. J. Physiol., 31: 427-431.

Tanaka, Y., Morimoto, T., WataRi, H., and Miyazaki, M. (1976) Continuous monitoring of circulating blood hematocrit. Jpn. J. Phyliol., 26: 345-353.

ZOLLINGER, R. M. (1972) Plasma volume and protein restoration after hemorrhage: Role of the left thoracic duct versus transcapillary refilling. J. Surg. Res., 12: 151-161. 